\title{
JULIO CASTELLANOS
}

\author{
POR
}

\section{JUSTINOFER NÁNDEZ}

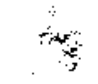

(

8
E) Instituto de Investigaciones Estticas de la Universidad Nacional lamenta la muevte del pintor mexicano Jutio Castellanas, acaeción al 15 de julio de 19.47 $y$ reproduce aqui les pelabras pronunciat das por Justino Ferpínder en la capilla ardiente, en la Escuela de Artes P1́sticas de la Universidad Nacional, de la cual el artista for profecor destacado.

Hi muerto tan artista, uno de thestros mis honridos $y$ finos poetas, que supo llevar con dignidad la cruz que la vida es. Mutro o no muerto, d. Julio Casteflanos no se puede hablar in conmowerse, porque su obra es ou vida, ea ls condentectón de sti propio sar atustero, espuctante y capar de expresurse en tírminos de elevada poetia.

Ei el primer poeta, verdadera y entrafiablemente nuestro, que termina bu jornada equí, dejándonos el ejemplo de su vida de artista en un conjunto de obras que expresen ante todo sa capacidad de comprentión de lo que el arte es. 
Si es verdad que el hombre es poeta por constitución, porque tiene que transformar el mundo para hacerlo propio, para hacerse a sí mismo, es también verdad que no todos somos capaces de hacernos artistas, de llevar nuestras propias posibilidades a la altura que Julio Castellanos las llevó, arduamente, sin premuras, con un gran sentido de responsabilidad, sin sucumbir a la fácil empresa, sino más bien escogiendo las espinas, transformándolas en alegorias de la vida.

Probó y trabajó todas las técnicas, pintó óleos y murales al fresco, litografias de una sensibilidad, de una belleza, de una pureza incomparables; hizo escenografías, fué maestro y con toda propiedad, fué un hombre.

Julio Castellanos supo elevar lo circunstancial y anecdótico a planos universales; apartándose del pintoresquismo vulgar, superó cuanto en ese aspecto se ha hecho; vió a su mundo circundante, a México, con profundidad, y nos entregó su visión penetrante en la que siempre flota el aire de una interrogación. Interrogador de la realidad fué Castellanos -creo firmemente que jamás tuvo otra actitud-, pero interrogó con inteligencia y con su fina intuición penetró la realidad; por eso pudo expresar esa íntima angustia de su ser en El Diálogo, en el Baño de San Juan, en La Lluvia y en El Bohio; su obra fué premiada en la Exposición Nacional de 1946.

Personal, delicado, puro en su línea como lo fué en su corazón, Castellanos es uno de nuestros clásicos, uno de los más exquisitos dibujantes de todos los tiempos. En justicia puede decirse que su obra quedó completa, a pesar de las enormes posibilidades que poseía, y todo lo que es queda resumido en su cuadro póstumo, su magistral autorretrato, que será la clave para entender todo lo que en vida fué. Caballete y cruz al mismo tiempo en. un fondo de infinitud y en el centro un objeto, pero un objeto que vibra, un rostro hecho de espinas y unos ojos que siguen interrogando al más allá, con la mirada extendida, prolongando su ser hacia el espacio sobrehumano, sin contestación. Quizá sorprenda este sentido metafísico de la obra de Castellanos, pero como gran artista, su preocupación central es el Ser; por eso es grande.

Meditó, sin duda, más que pintó; habló poco y habló bien; dijo algo con sentido para nuestro tiempo, y son raros los que pueden hacerlo. Es por esta coincidencia y por la calidad de la expresión de su ser por lo que Castellanos queda vivo, ocupando un lugar prominente entre los hombres que. en verdad son humanos. Ia muerte que él vivió nos descubre su ser ejemplar. Hagamos votos porque haya encontrado, al fin, la contestación que buscaba su mirada espectante. 
DOI: http://dx.doi.org/10.22201/iie.18703062e.1948.16.455

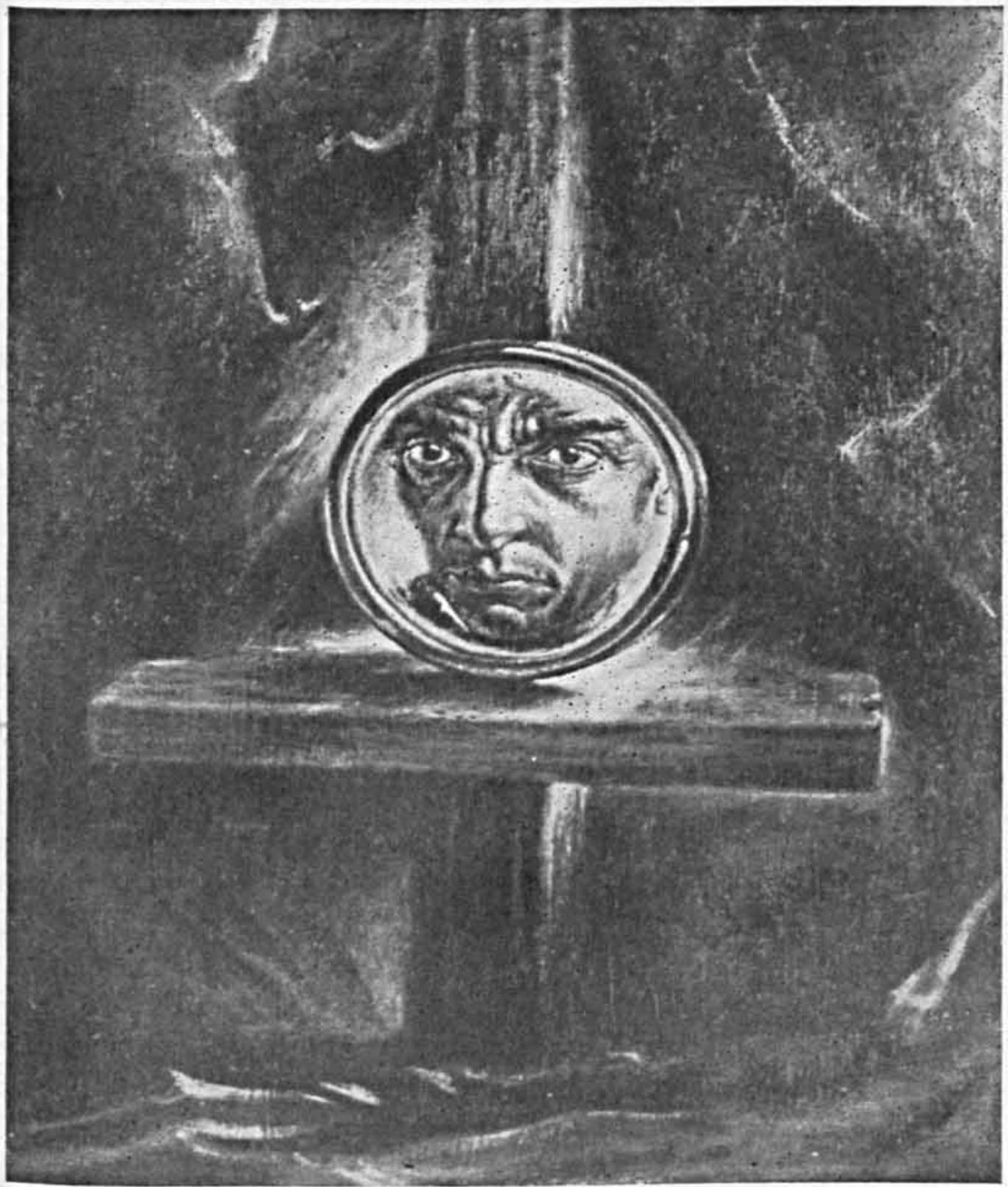

Julio Castellanos. Autorretrato. Julio 1947. Ultima obra 